Fourth, as important as it is to develop better emergency treatment for Aboriginal trauma patients, we must also move beyond this to address other health-services issues. Geographic location often limits timeliness, access and level of health care available in rural and isolated regions, which constitute well-documented predictive factors for trauma outcomes. ${ }^{7.8}$ Health services may lack culturally sensitive care, perhaps exacerbated by the persisting underrepresentation of Aboriginal professionals in health care. ${ }^{1,9}$ Delivery of health care in remote and rural regions across Canada is an ongoing struggle; a novel approach is the development of northern medical-school campuses in British Columbia (by the University of British Columbia) and Ontario (by the Northern Ontario School of Medicine) to train physicians "in the north, for the north." Although vital, solutions to the trauma epidemic in our Native populations must look past the emergency departments and surgical suites that care for the injured, to the individual, community, environmental, social and economic factors that set the scene for these traumas.

Last, and perhaps most importantly, each step in this vital process cannot be done for Canada's Aboriginal population; it can only be done with us. These issues cannot be addressed without understanding Canada's history with its Aboriginal people, as each of these steps, from surveillance to solution to program implementation, can no longer be imposed on or adapted to the community without its approval and participation.

Traumatic injury and death may be the most preventa- ble of all health issues. It is time that we, as health care professionals and researchers, treated them as such.

Nadine Caron is Assistant Professor of Surgery, University of British Columbia, Northern Medical Program, Prince George, BC.

Competing interests: None declared.

\section{References}

1. MacMillan HL, MacMillan AB, Offord DR, Dingle JL. Aboriginal health [review]. CMA7 1996;155(11):1569-78.

2. Young TK. Review of research on aboriginal populations in Canada: relevance to their health needs. BM7 2003;327:419-22.

3. Karmali S, Laupland K, Harrop AR, Findlay C, Kirkpatrick AW, Winston B, et al. Epidemiology of severe trauma among status Aboriginal Canadians: a population-based study. CMAJ 2005;172(8):1007-11

4. Lett R, Kobusingye O, Sethi D. A unified framework for injury control: the public health approach and Haddon's Matrix combined. Inj Control Saf Promot 2002;9:199-205.

5. Murray CJ, Lopez AD. Mortality by cause for eight regions of the world: Global Burden of Disease Study. Lancet 1997;349(9061):1269-76.

6. Conroy C, Fowler J. The Haddon matrix: applying an epidemiologic research tool as a framework for death investigation. Am 7 Forensic Med Pathol 2000;21: 339-42.

7. Auer AM, Andersson R. Canadian Aboriginal communities and medical service patterns for the management of injured patients: a basis for surveillance. Public Health 2001;115:44-50.

8. Auer AM, Andersson R. Canadian Aboriginal communities: a framework for injury surveillance. Health Promot Int 2001;16:169-77.

9. Dhalla IA, Kwong JC, Streiner DL, Baddour RE, Waddell AE, Johnson IL. Characteristics of first-year students in Canadian medical schools. CMAJ 2002;166(8):1029-35

Correspondence to: Dr. Nadine R. Caron, Northern Medical Program, University of Northern British Columbia, 3333 University Way, Prince George BC V2N 4Z9; fax 250 960-5518; caronn@unbc.ca

\title{
A call to bloggers (not a running group)
}

\section{Stephen Choi}

$\mathrm{L}$

ast week CMAf posted its first blog (www.cmaj.ca /misc/drblog1.shtml). James Maskalyk (a.k.a. Dr.

$\mathrm{Blog}$ ), a former editorial fellow at CMA7, is its author and the engineer of this experiment at the journal. Working with Médecins Sans frontières (MSF), he provides readers with an insightful gaze at the health care system in Bolivia, and specifically their efforts to prevent and treat endemic Chagas' disease. Maskalyk will soon travel to Africa to work in MSF-sponsored HIV treatment programs.

A blog (short for Web log) is a sort of diary, a regularly updated journal on the Web. Blogs allow people to publish their writings electronically without the impediments of traditional print. In a blog, a person can instantaneously muse about anything from medicine to politics to Brad and Jennifer. Their content and quality varies as widely as the topics; many are self-indulgent, but a great number are genuine attempts to inform. The earliest and most vivid accounts of last December's tsunami victims were found in

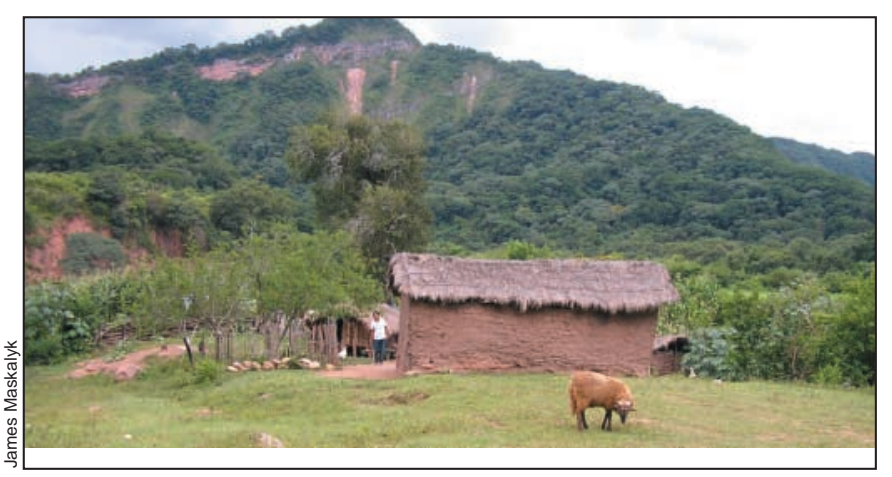

Excerpt 1 from Dr. Blog: It is a hard truth that ours is a world driven more by profit than by compassion.... It is puzzling that with the strong evidence linking poverty and health there remains such inaction. Its cycle is almost a karmic one, excepting the most deserving receive the least. Man bitten by vinchuca [a bloodsucking insect] gets sick, family spends its money on ineffective treatment and he dies, the farm goes fallow, banana production falls, Bolivia's economy suffers, less chance of treatment for his neighbour. And [then] bananas are more expensive. 


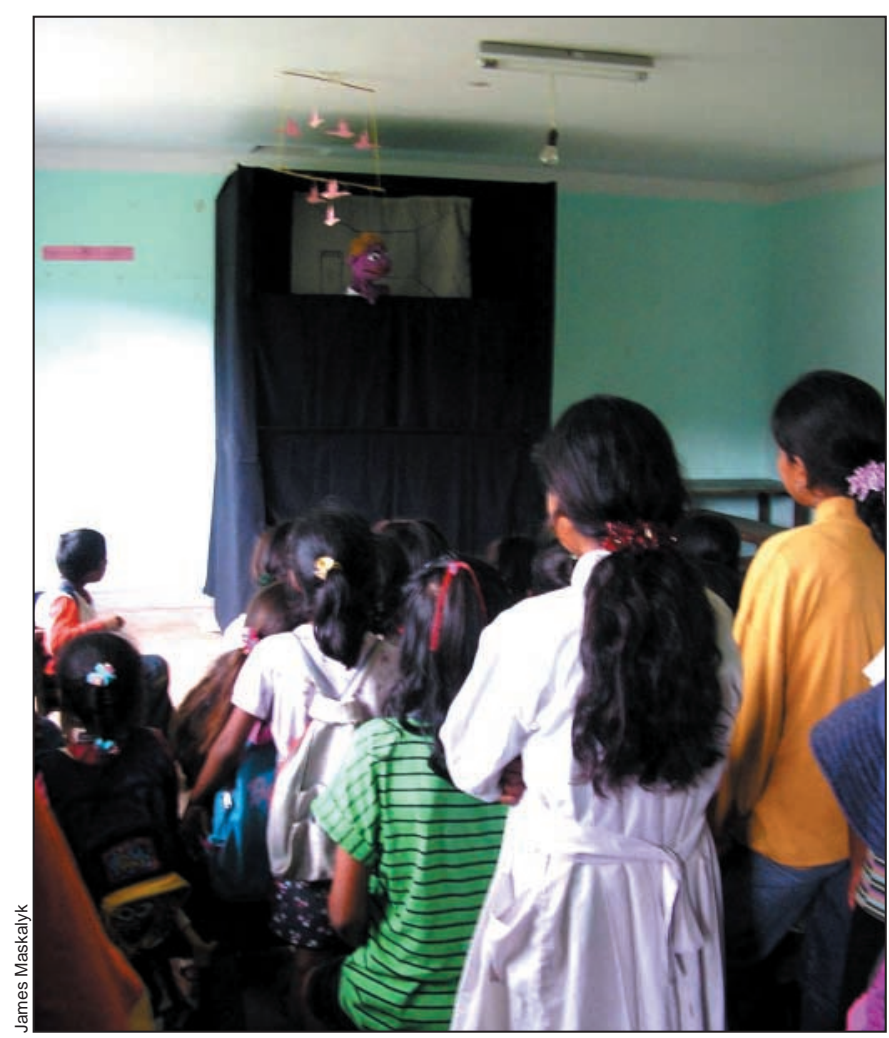

Excerpt 2 from Dr. Blog: The pillars of [Médecins Sans Frontières] work are education and prevention in concert with investigation and treatment. At a local school, a puppet show is in progress ... [A] tearful father ... has just lost his best friend to "sudden death," a common moniker for heart related complications of Chagas disease. Woefully he explains about the vinchuca, how it is the cause of so much misery in the community. That night the terrifying vinchuca appears and bites the sleeping boy. A young girl in the audience starts to cry, and is escorted out.

blogs (www.phukettsunami.blogspot.com). Universities are using blogs to facilitate communication between students and faculty members. Politically oriented blogs figured prominently in the resignation of CNN's news executive over comments about journalists in Iraq, as well as the retraction by CBS's Dan Rather of a story about George W. Bush's military service record.

Is blogging a legitimate form of journalism? Publishing online does not make one a journalist; interviews, factchecking, editing and professional ethics are tenets of the journalistic process that are largely absent in blogging. But proponents argue that bloggers provide a valuable perspective, unfettered by the structural biases of the increasingly concentrated media establishment. Without this new communications medium, the voice of the average blogger would not be heard.

Have blogs any role at a medical journal? We aim to find out if they are sustainable. In this, our first exploration, we have not tried to push the boundaries very

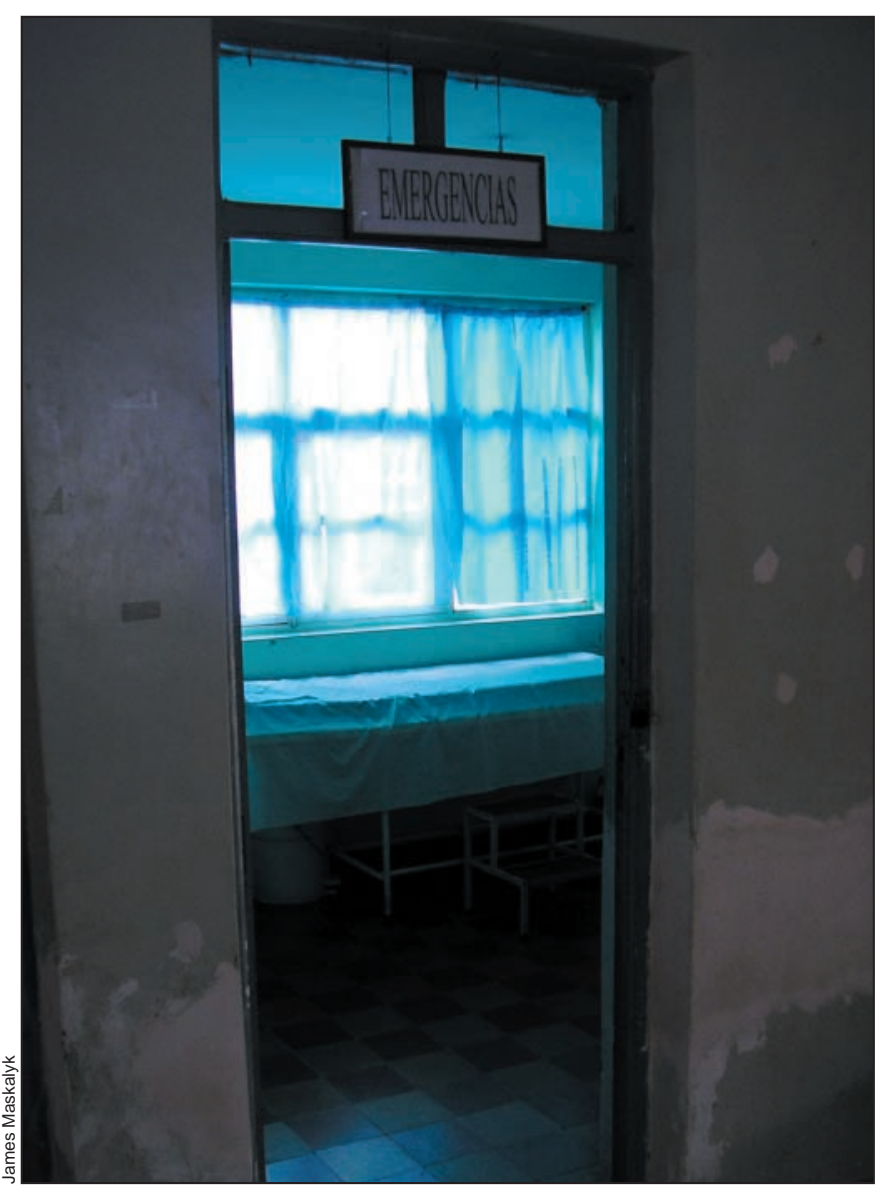

Excerpt 3 from Dr. Blog: I have been telling the staff here that I am a doctor, and one that works in the emergency department in some of Canada's biggest hospitals. They seemed somewhat confused, and were certainly unimpressed. I understand why... X-ray? Broken. Laboratory? Sometimes. Blood? No. Electrocardiograms? No. Oxygen saturation? None.

hard: Maskalyk is active in global health medicine and armed with deft prose. But we recognize the potential to host additional blogs, open to the international community, that would allow free discourse on a wide range of themes such as primary care, rural medicine and medical education, to name a few. We welcome ideas from motivated readers who are interested in launching blogs on CMA7's Web site.

In the spirit of blogging, we hope to furnish a medium that encourages the exchange of information and provides insights that are free from the pressures of academic advancement, harsh peer reviewers and tyrannical editors.

Stephen Choi is Deputy Editor of CMA7.

Competing interests: None declared.

Correspondence to: Dr. Stephen Choi, CMAJ, 1867 Alta Vista

Dr., Ottawa ON K1G 3Y6; fax 613 565-5471;

stephen.choi@cma.ca 